\title{
Prevalence of food insecurity among military households with children 5 years of age and younger
}

\author{
Sarah Grenier Wax ${ }^{1, *}$ and Susan M Stankorb ${ }^{2}$ \\ ${ }^{1}$ Military-Baylor Graduate Program in Nutrition, AMEDD Center \& School, 3599 Winfield Scott Road, Suite 308, \\ Fort Sam Houston, San Antonio, TX 78234, USA: ${ }^{2}$ Department of Nutritional Medicine, Brooke Army Medical \\ Center, Fort Sam Houston, San Antonio, TX, USA
}

Submitted 22 September 2015: Final revision received 23 January 2016: Accepted 16 February 2016: First published online 15 March 2016

\begin{abstract}
Objective: Food insecurity increases risk of health conditions that may decrease military readiness. The aim of the present study was to define the prevalence of food insecurity among households with young children utilizing military installation childcare facilities and to describe household characteristics associated with food insecurity among this population.

Design: Cross-sectional survey including demographic questions and the US Department of Agriculture Food Security Survey Module six-item short form given to households ( $n$ 248) enrolled in Joint Base San Antonio Child Development Centers (JBSA-CDC) during the spring of 2015.

Subjects: Department of Defense families with at least one child less than 6 years old enrolled in a JBSA-CDC.

Settings: Joint Base San Antonio, TX, USA.

Results: Nearly one in seven families reported food insecurity. Households were more likely to be food-insecure if the head of household's highest level of education was high school or equivalent $(P=0.003)$ and if the head of household was unmarried/unpartnered $(P=0 \cdot 001)$. Among food-insecure households headed by military service members, all were junior enlisted or noncommissioned officers (E1-E9). Food-insecure households were less likely to live off-post in owned or rented homes compared with those who were food-secure $(P=0.016)$. Other characteristics associated with food insecurity included at least one family member enrolled in the Exceptional Family Member Program $(P=0.020)$ and more children in the household $(P=0.029)$. Few families reported enrolment in government supplemental food programmes.

Conclusions: Food insecurity is prevalent in military families. Targeted interventions and policies can be developed using the demographic risk factors identified in the present study.
\end{abstract}

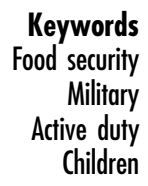

Food insecurity is prevalent in the USA. In 2013, the Economic Research Service reported that 17.5 million US households were food-insecure ${ }^{(1)}$. Military service members and their families are not immune to food insecurity, and its physical and mental effects may decrease military readiness and increase direct and indirect medical costs for service members and their families. Currently, there is limited published literature regarding the prevalence of food insecurity among military families.

Food insecurity is defined as having limited or uncertain availability of nutritionally adequate and safe foods or limited or uncertain ability to acquire acceptable foods in socially acceptable wayss ${ }^{(2,3)}$. In 2013 , food insecurity was reported in $14.3 \%$ of US households, with the highest levels found in houses with incomes at or near the federal poverty line ${ }^{(1)}$. Income for a new enlisted service member with a large family may be within $130 \%$ of the poverty guideline and qualify the household for government supplemental nutrition programmes such as the Supplemental Nutrition Assistance Program (SNAP) ${ }^{(4-6)}$. For instance, the US Department of Health and Human Services' federal poverty guideline for a family of four was annual income of \$US 24250 in $2015^{(7)}$. For a family of four to qualify for SNAP, the household's gross annual income would be about \$US 31540 , or $130 \%$ of the federal guideline ${ }^{(4)}$. A US Army Private with three family members living in military installation housing may meet these income guidelines ${ }^{(8)}$.

There are several indicators that food insecurity may be common among military families. US Department of 
Agriculture (USDA) financial reports from 2013 show that \$US 103.6 million of groceries were purchased with SNAP benefits, previously called food stamps, at military commissaries, a 5\% increase from $2012^{(9,10)}$. The USDA recently estimated that between 2000 and 22000 military households receive SNAP benefits ${ }^{(11)}$. Since participation in government assistance programmes is associated with food insecurity, the increasing SNAP redemption may indicate rising food security issues. Additionally, Family Subsistence Supplemental Allowance (FSSA) is a voluntary financial benefits military programme designed to prevent service members and their families from relying on SNAP by increasing income ${ }^{(12)}$. There were only 510 FSSA participants in 2010, but at least 1000 SNAP participants listed active-duty military as their source of employment in the USA in $2010^{(13,14)}$. A recent report found that 8486 service members applied for FSSA in calendar year 2013, but only 285 applicants were approved across all Department of Defense (DoD) branches ${ }^{(6)}$. Thus, military members may be experiencing food insecurity and having difficulty accessing military-specific resources. A recent study of US veterans of the Afghanistan and Iraq wars showed that they are experiencing food insecurity at rates double the general US population with one in four meeting criteria for food insecurity ${ }^{(15)}$, yet there are no published studies which establish the prevalence of food insecurity among military families currently serving on active duty.

Food insecurity is associated with a host of physical and mental health problems that may have long-lasting impacts well beyond the period of food insecurity ${ }^{(16)}$. Children in food-insecure households are at higher risk for irondeficiency anaemia, poor health, chronic illnesses, psychosocial issues, asthma, obesity, and decreased mental proficiency in memory, expressive and receptive vocabulary, reasoning and problem solving, and concept attainment ${ }^{(17-22)}$. Among adults, food insecurity is associated with diabetes, CVD, depression, anxiety and poor sleep ${ }^{(23-27)}$. These factors may stress the military family, increase utilization of health-care resources and be detrimental to performance, physical and mental wellbeing, thereby degrading military readiness and resiliency.

Several studies have utilized the USDA Food Security Survey Module, a validated tool for assessing food insecurity, to examine associations between food security levels and demographic variables in households with children in the general US population ${ }^{(28-30)}$. Food insecurity was associated with low income, low education, racial and ethnic minorities, renting a home, living in a central city, having three or more children, being a single parent, having no elderly living in the household, having a disabled household member and maternal depression ${ }^{(28-30)}$.

Military families have unique demographic considerations that may place them at increased risk for food insecurity. In the USA, households with children, especially those with children younger than 6 years of age, have higher rates of food insecurity than those without children ${ }^{(1)}$. More than $40 \%$ of active-duty service members had children in $2013^{(31)}$. Service members often marry younger and start families earlier than their civilian counterparts, potentially placing these members with families at higher risk ${ }^{(32)}$. Limited employment of military spouses also contributes to lower household incomes, putting military families closer to the poverty line ${ }^{(32)}$. Military spouses are found to take lower-wage jobs in which their skill set exceeds that of the job requirement due to frequent moves between duty stations ${ }^{(14,33)}$. Military wives in general are less likely to work if their husband is deployed and they have children under the age of 6 years ${ }^{(34)}$. Military households whose incomes are scarcely above the federal poverty line, primarily junior enlisted service members with minimal years of service and larger families, are anticipated to be at increased risk for food insecurity ${ }^{(11)}$. Conversely, the military may provide a setting where traditional demographics associated with food insecurity, such as race and ethnicity, may be less influential. For instance, a study by Lundquist et al. found that racial gaps in breastfeeding rates were minimized among the military population $^{(35)}$.

Despite the potential risk for food insecurity in a military population, its prevalence has not been fully explored. Budget proposals to reduce overall defence spending may impact service members' pay and benefits such as access to commissaries ${ }^{(36)}$. However, annual financial reports by the Defense Commissary Agency demonstrate average customer savings of $30 \%$ compared with civilian grocers ${ }^{(37)}$. Therefore, it is important that policy makers have an accurate estimate of the prevalence of food insecurity issues among the active-duty service members. The objective of the present study was to measure the extent of food insecurity among military households with children using the six-item short-form USDA Food Security Survey Module and to identify demographic variables of military families associated with food insecurity.

\section{Methods}

\section{Participants}

Brooke Army Medical Center's Institutional Review Board approved the study. Households with at least one child aged 5 years or younger enrolled in a Joint Base San Antonio Child Development Center (JBSA-CDC) were recruited. CDC are located on military installations and provide childcare services to active-duty service members, National Guard and Reserve members, and DoD civilians and contractors. The main childcare services of CDC are provided to children 5 years of age and younger, a potentially at-risk population for food insecurity. Associate investigators recruited English-speaking parents and legal guardians, 18 years of age or older, of children 
enrolled in JBSA-CDC. G Power version 3.1.9 (Universität Kiel, Germany) was used to conduct an a priori power analysis for the primary hypothesis of a significant difference between children in households among levels of food security. A total of 128 households were needed to achieve adequate statistical power.

\section{Survey tool}

The demographic portion of the questionnaire was created by the principal investigator, an experienced survey writer, using techniques described by Dillman et al. for design of Internet and mixed-mode surveys ${ }^{(38)}$. The survey tool was then reviewed by a panel of six outside subject-matter experts in the areas of research, survey design and/or food security, and the survey was revised based on their feedback. Head of household demographics assessed include sex, age, education, race, ethnicity, marital status, employment type and pay grade. Household characteristics assessed, or factors that describe the household, were location of housing, recent move, recent deployment, participation in the Exceptional Family Member Program (EFMP), gardening, relying on others for food and tobacco use. Household composition and number of income earners were examined. Lastly, current and potential utilization of government and community resources that may address food insecurity were assessed including participation in government assistance programmes, grocery location and interest in community programmes like cooking classes and food pantries.

Food security status was calculated using the six-item short form of the USDA Food Security Survey Module. The six-item short form is a reliable and valid tool for measuring food insecurity status in households with children $^{(39,40)}$ and it measures food insecurity in the past 12 months $^{(41)}$. The short form classifies food insecurity into 'high or marginal food security' (score <2), 'low food security' (score 2-4) and 'very low food security' (score $>4$ ) based on the number of affirmative responses ${ }^{(41)}$. Low food security is described as decreased diet quality and variety but minimal reduction in food intake ${ }^{(42)}$. Very low food security is defined as 'disrupted eating patterns and reduced food intake, ${ }^{(42)}$. For the purposes of the present analysis, low and very low food security groups were combined due to small group sizes.

\section{Data collection}

Recruitment was conducted at each CDC for one week. Advertisements were posted at each facility and an electronic invitation to participate with elements of informed consent was sent to parents and legal guardians via email. A hard copy of the invitation to participate was also placed in children's lockers. After announcement of the research, respondents had the opportunity to complete the questionnaire in person at each CDC or electronically.
Electronic survey links were sent out to parents and legal guardians twice during the recruitment week. Additionally, a labelled envelope was provided for parents and legal guardians who wanted to return a paper copy survey by mail.

\section{Statistical tests}

Statistical analyses were performed using the statistical software package IBM SPSS Statistics Version 22.0 (2013). Descriptive statistics were used to analyse demographic variables, household characteristics, household composition, and to determine food security status. Pearson's $\chi^{2}$ test was used to determine the relationships between level of food security and selected head of household demographics and household characteristics: employment status, recent deployment and recent move. To determine the relationship between food security status and number of children in the household, a Mann-Whitney $U$ test was conducted.

\section{Results}

Of the screened households ( $n$ 275), twenty were ineligible to complete the survey and seven households were excluded for not answering greater than $50 \%$ of questions or for providing ambiguous answers regarding number of children in the household. The final number of participating households was 248. More households chose to participate on paper hard copy (56.0\%) than electronically (44.0\%).

\section{Prevalence of food insecurity}

A total of 242 households provided all data to determine food security level. Nearly $15 \%$ or approximately one in seven households reported issues with food security. Among the total sample, which included DoD civilians and contractors as well as active-duty service members, $9 \cdot 1 \%$ of households reported low food security and $5.8 \%$ reported very low food security. Among only those households with at least one active-duty service member, $85.9 \%$ ( $n$ 164) reported high/marginal food security and $14.1 \%$ ( $n$ 27) reported food insecurity ( $9.4 \%$ low food security, $4.7 \%$ very low food security).

\section{Head of bousebold demographics and bousebold food security}

Seventy-three per cent of surveys were completed by the head of household; the remainder provided responses regarding the demographics of their head of household. Heads of household were mostly female (55.9\%), Caucasian $(61.1 \%)$, non-Hispanic $(76.0 \%)$, active-duty military $(76 \cdot 1 \%)$, married or living with a partner (78.0\%), and had an associate's degree or bachelor's degree $(56.5 \%)$ as their highest level of education. 
Table 1 Head of household demographics; military households with children 5 years of age and younger enrolled in military installation childcare facilities, Joint Base San Antonio, TX, USA, spring 2015

\begin{tabular}{|c|c|c|c|c|c|c|}
\hline & \multicolumn{4}{|c|}{ Food security level } & \multirow[b]{2}{*}{ Total $^{*}$} & \multirow[b]{3}{*}{$P \dagger$} \\
\hline & \multicolumn{2}{|c|}{ High/marginal (n 206) } & \multicolumn{2}{|c|}{ Low/very low (n 36) } & & \\
\hline & $n$ & $\%$ & $n$ & $\%$ & $n$ & \\
\hline Female & 112 & $54 \cdot 6$ & 21 & $61 \cdot 8$ & 239 & 0.438 \\
\hline Education $\ddagger$ & & & & & 242 & 0.003 \\
\hline High school or equivalent & 32 & $15 \cdot 6$ & 13 & $36 \cdot 1$ & & \\
\hline Associate's/bachelor's degree & 116 & $56 \cdot 6$ & 20 & $55 \cdot 6$ & & \\
\hline Master's/doctorate or professional degree & 57 & $27 \cdot 8$ & 3 & $8 \cdot 3$ & & \\
\hline Race & & & & & 220 & 0.970 \\
\hline African American & 41 & $21 \cdot 8$ & 7 & 21.9 & & \\
\hline Caucasian & 115 & $61 \cdot 2$ & 19 & $59 \cdot 4$ & & \\
\hline Other§ & 32 & $17 \cdot 0$ & 6 & $18 \cdot 8$ & & \\
\hline Hispanic/Latinoł & 48 & $23 \cdot 8$ & 7 & $20 \cdot 0$ & 240 & 0.626 \\
\hline Marital status & & & & & 240 & 0.001 \\
\hline Married or living with partner & 166 & $81 \cdot 4$ & 20 & $55 \cdot 6$ & & \\
\hline Single, separated, divorced or widowedll & 38 & $18 \cdot 6$ & 16 & 44.4 & & \\
\hline Employmentł & & & & & 241 & 0.937 \\
\hline Active duty & 155 & $75 \cdot 6$ & 27 & $75 \cdot 0$ & 182 & \\
\hline Junior enlistedף & 15 & $9 \cdot 7$ & 4 & $15 \cdot 4$ & & \\
\hline Non-commissioned officer & 110 & $71 \cdot 0$ & 22 & $84 \cdot 6$ & & \\
\hline Warrant officer & 0 & 0.0 & 0 & 0.0 & & \\
\hline Company grade officer & 12 & $7 \cdot 7$ & 0 & 0.0 & & \\
\hline Field grade and general officer & 18 & 11.6 & 0 & 0.0 & & \\
\hline Non-active duty & 50 & 24.4 & 9 & $25 \cdot 0$ & 59 & \\
\hline DoD civilian/contractor & 38 & $76 \cdot 0$ & 5 & $55 \cdot 6$ & & \\
\hline Non-DoD civilian & 12 & $24 \cdot 0$ & 3 & 33.3 & & \\
\hline \multirow[t]{2}{*}{ Unemployed } & 0 & 0.0 & 1 & $11 \cdot 1$ & & \\
\hline & Median & Range & Median & Range & & \\
\hline Age (years) & $33 \cdot 0$ & $19-57$ & 33.0 & $24-41$ & 235 & 0.443 \\
\hline
\end{tabular}

DoD, Department of Defense.

*Some categories do not add up to 242 due to missing values.

†The $\chi^{2}$ test was used to evaluate relationships between variables.

†Frequencies of 'unsure' are not displayed.

§Other includes Native American/American Indian, Asian/Pacific Islander, more than one race, other races, and would rather not say.

IIIncludes single/never married, married but separated, divorced and widowed.

TE4 rank is included in junior enlisted.

The median age for the head of household was 33 years (range: $19-57$ years).

Demographics of heads of household by food security level are reported in Table 1. For the purposes of the present study, high/marginal food-secure families are referred to as 'food-secure' and low/very low food-secure households are referred to as 'food-insecure'. Non-married/nonpartnered heads of household were 3.5 (95\% CI 1.66, 7.37; $\chi^{2}$, $P=0.001)$ times more likely to be food-insecure compared with married/partnered heads of household. If the head of household's highest education level was high school or a General Education Development (GED) equivalent, they were more likely to be food-insecure $\left(P=0.003, \chi^{2}\right)$. All food-insecure households were headed by military service members who were junior enlisted (E1-E4) or non-commissioned officers (E5-E9).

\section{Household characteristics and household food security}

The largest proportion of families lived in homes they owned located off the military installation (52.4\%) and had not moved from another duty station within the past year (81.2\%). A small proportion (8.5\%) were enrolled in the EFMP which is designed to help family members with special needs including physical, mental, hearing and vision disabilities among other serious health conditions. Most household members never used tobacco products (82.9\%). Among households with at least one active-duty military service member, a small proportion had been deployed within the past year (15.5\%).

Household characteristics by food security level are reported in Table 2 . A significantly larger proportion of foodinsecure households lived in either on-post family housing or off-post apartments compared with food-secure families who resided in owned and rented off-post homes $\left(P=0.016, \chi^{2}\right)$. Food-insecure households more frequently reported that they relied on others outside the home for food $\left(P<0.001, \chi^{2}\right)$. Households who reported having at least one family member enrolled in EFMP were 3.4 (95\% CI $\left.1 \cdot 26,9 \cdot 13 ; \chi^{2}, P=0 \cdot 020\right)$ times more likely to experience food insecurity than those who did not have a member enrolled. Families who had recently moved were not found to be at increased risk for food insecurity. 
Table 2 Household characteristics; military households with children 5 years of age and younger enrolled in military installation childcare facilities, Joint Base San Antonio, TX, USA, spring 2015

\begin{tabular}{|c|c|c|c|c|c|c|}
\hline & \multicolumn{4}{|c|}{ Food security level } & \multirow{3}{*}{$\frac{\text { Total }^{*}}{n}$} & \multirow[b]{3}{*}{$P \dagger$} \\
\hline & \multicolumn{2}{|c|}{ High/marginal (n 206) } & \multicolumn{2}{|c|}{ Low/very low (n 36) } & & \\
\hline & $n$ & $\%$ & $n$ & $\%$ & & \\
\hline Housing $\ddagger$ & & & & & 242 & 0.016 \\
\hline On-post/base family housing & 23 & $11 \cdot 3$ & 9 & $25 \cdot 7$ & & \\
\hline Off-post/base apartment & 19 & 9.3 & 7 & $20 \cdot 0$ & & \\
\hline Off-post/base rental home & 47 & 23.0 & 5 & $14 \cdot 3$ & & \\
\hline Off-post/base owned home & 115 & $56 \cdot 4$ & 14 & $40 \cdot 0$ & & \\
\hline Recent move & 39 & 18.9 & 7 & $19 \cdot 4$ & 242 & 0.990 \\
\hline No tobacco use & 171 & 83.4 & 30 & 83.3 & 242 & 0.975 \\
\hline Participation in EFMP & 14 & 6.9 & 7 & $20 \cdot 0$ & 242 & 0.020 \\
\hline Recent deployment & 27 & $14 \cdot 3$ & 6 & $19 \cdot 4$ & 220 & 0.427 \\
\hline Relying on others for food & 2 & 1.0 & 11 & $30 \cdot 6$ & 242 & $<0.001$ \\
\hline Gardening & 38 & 18.5 & 8 & $22 \cdot 2$ & 241 & 0.604 \\
\hline
\end{tabular}

EFMP, Exceptional Family Member Program.

*Some categories do not add up to 242 due to missing values.

†The $\chi^{2}$ test was used to evaluate relationships between variables.

†Other housing was excluded from analysis due to small group size.

$\S$ Daily and occasional tobacco use were combined for analysis.

Table 3 Household composition; military households with children 5 years of age and younger enrolled in military installation childcare facilities, Joint Base San Antonio, TX, USA, spring 2015

\begin{tabular}{|c|c|c|c|c|c|c|}
\hline & \multicolumn{4}{|c|}{ Food security level } & \multirow{3}{*}{$\frac{\text { Total }^{*}}{n}$} & \multirow[b]{3}{*}{$P \dagger$} \\
\hline & \multicolumn{2}{|c|}{ High/marginal (n 206) } & \multicolumn{2}{|c|}{ Low/very low (n 36) } & & \\
\hline & Median & Range & Median & Range & & \\
\hline Size of household & 4.0 & $2-8$ & $4 \cdot 0$ & $2-7$ & 233 & 0.395 \\
\hline Number of adults & $2 \cdot 0$ & $1-4$ & $2 \cdot 0$ & $1-4$ & 233 & 0.035 \\
\hline Number of full-time income earners & 2.0 & $0-3$ & 1.0 & $0-2$ & 233 & $<0.001$ \\
\hline Number of part-time income earners & 0.0 & $0-2$ & 0.0 & $0-2$ & 233 & 0.234 \\
\hline Number of active-duty members & 1.0 & $0-3$ & 1.0 & $0-2$ & 233 & 0.330 \\
\hline Number of grandparents & 0.0 & $0-2$ & 0.0 & $0-1$ & 233 & 0.687 \\
\hline Number of children ( $<18$ years) & $2 \cdot 0$ & $1-6$ & $2 \cdot 0$ & $1-4$ & 233 & 0.029 \\
\hline Age of youngest child (years) & 2.0 & $0-5$ & 2.5 & $0.5-5$ & 233 & 0.193 \\
\hline Age of oldest child (years) & 3.5 & $0-17$ & $7 \cdot 0$ & $1-17$ & 233 & 0.004 \\
\hline
\end{tabular}

${ }^{*}$ Categories do not add up to 242 due to missing values.

†The Mann-Whitney $U$ test was used to evaluate relationships between variables.

\section{Housebold composition and bousebold food security}

The mean household size was $3 \cdot 8$ (SD 1.1) with the largest proportion of families having two adults $(78.8 \%)$ and one or two children $(80.5 \%)$. Most families had one or more active-duty service member living in the household (79.9\%). The largest proportion of children were of preschool age (45.0\%) followed by infants $(21.7 \%)$.

Household composition by food security status is reported in Table 3. Food-insecure families had fewer adults $(P<0 \cdot 035$, Mann-Whitney $U)$ and fewer full-time income earners $(P<0 \cdot 001$, Mann-Whitney $U)$ living in the household. Families that were food-insecure had higher numbers of children $(2 \cdot 1$ (SD 0.9)) in the household than food-secure families (1.8 (SD 0.9); $P=0.029$, MannWhitney $U$ ). Food-insecure households had significantly older children (mean age 7.5 (SD 4.8) years) compared with food-secure households (mean age 5.4 (SD 4.6) years; $P<0 \cdot 004$, Mann-Whitney $U$ ).

\section{Government and community resource utilization and bousebold food security}

To assess use of available resources and potential use of community and government programmes that improve access to adequate food, participants were asked about enrolment in nutrition programmes including SNAP, the Special Supplemental Nutrition Program for Women, Infants, and Children (WIC), the National School Lunch Program (NSLP), FSSA, a food bank/food shelf programme, or any other programmes to offset the cost of food. Participants chose from the following options: 'never enrolled', 'currently enrolled', 'unenrolled in the past year', 'unenrolled more than a year ago' or 'unsure'. 
A small number of households participated in government supplemental food programmes. The most frequently used programme was WIC. Out of food-secure households, $13.4 \%$ ( $n$ 27) unenrolled more than a year ago from WIC. Twenty per cent $(n 7)$ of food-insecure households were currently enrolled in WIC, while 20.0\% ( $n$ 7) had previously enrolled in this programme. Despite being a military-specific programme, no households ( $n$ 236) had ever enrolled in the FSSA programme. Eight households were currently enrolled in more than one programme.

Households were asked to indicate how likely they would be to participate in community programmes such as budgeting classes, cooking classes, community gardens and a food pantry. A large proportion of food-insecure households reported they were 'likely' or 'very likely' to participate in all community programmes. Food-insecure families were most interested in participating in cooking (67.6\%) and budgeting (66.7\%) classes. Families were also asked to identify their two most frequent locations where they shop for food. In food-insecure households, civilian grocers $(86.1 \%)$ and military commissaries $(47 \cdot 2 \%)$ were the most preferred vendors.

\section{Discussion}

\section{Prevalence of bousebold food insecurity}

The present unique study describes food security status among DoD households with children. Prevalence of food insecurity for the total sample (14.9\%) and for households with active-duty service members ( $14 \cdot 1 \%$ ) were comparable to the 2010-11 national average for households with children and at least one full-time worker $(15 \cdot 7 \%)^{(43)}$. Even though the prevalence rates are similar, these findings are startling considering the potential impact that food insecurity can have on the readiness and resiliency of DoD families.

\section{Demographic and bousebold characteristics associated with bousebold food security}

We hypothesized that those households with recently deployed members or those who moved within the past year would have increased risk of food insecurity. Similar to the study by Widome et al. ${ }^{(15)}$, deployment was not associated with food insecurity, which may be connected to deployment-related allowances such as Family Separation Allowance, Hostile Fire Pay/Imminent Danger Pay and Hardship Duty Pay. Also, households that moved within the past year did not experience higher rates of food insecurity. After a move, spouses and other household members may have easily found employment in San Antonio's growing job market ${ }^{(44)}$; therefore, this result should be interpreted with caution, as many military installations are not located in large cities with strong job markets. Lastly, we hypothesized that food-insecure families would be headed by active-duty service members and have higher numbers of children living in the household. Our results support literature that found food-insecure households tend to have more children than food-secure families ${ }^{(15,28,43)}$. However, there was no difference in food security status between active-duty and non-active duty heads of household. Regardless, food insecurity was a prevalent issue in DoD families as a whole.

Similar to other research, marriage status of the head of household was associated with food insecurity in DoD families. For instance, a recent study of US veterans found that those who were married/partnered had significantly reduced odds of having very low food security compared with unmarried veterans ${ }^{(15)}$. Participation in the EFMP, the programme that helps family members with special needs including physical, mental, hearing and vision disabilities, was found to increase risk of food insecurity by threefold. This result is consistent with literature that has found an association between disability in the household and food security status ${ }^{(28,43)}$. Households with a disabled member may be at increased risk of food insecurity due to reduced earnings of a disabled non-working household member and higher disability-related expenses ${ }^{(45,46)}$. Even though this population has access to robust health care which may alleviate disability-related medical expenses, an association remains between food insecurity and disability in the household. Lastly, no officers (O1-O10) reported problems accessing food in the current study. Few officer veterans (CW1-O10) in the study by Windome et al. reported low food security $(2.9 \%)$ and very low food security $(3.7 \%)^{(15)}$. It is likely that junior enlisted (E1-E4) and non-commissioned officers (E5-E9) experience higher rates of food insecurity since rank is directly linked to pay and monetary allowances.

Our results differed from others' findings regarding demographics of food-insecure heads of household. Previously, education status of the head of household has inconsistently shown an association with food security level ${ }^{(28-30,43)}$. The current study found that those with only a high-school degree, or GED equivalent, were more likely to head a food-insecure household even with DoD employment. Furthermore, racial and ethnic minorities were not associated with being food-insecure, which differs from national trends ${ }^{(1,43)}$. This suggests that the military environment mitigates racial and ethnic influences on food security status; this pattern has been seen in other research where racial gaps in breast-feeding rates were minimized among the military population $^{(35)}$.

Tobacco use was not associated with food security status in the current study; however, household tobacco use was relatively low compared with DoD reports of smoking among active-duty military ${ }^{(47)}$. This may be due to the fact that JBSA has a large population working in medical-related professions. Our results contrast Widome et al.'s findings ${ }^{(15)}$ that found US veterans who smoked 
were more likely to be food-insecure. Veterans are more likely to report risky health behaviours compared with non-veterans which could also explain the discrepancy; yet since there were so few smokers in the current study, these results should be interpreted with caution ${ }^{(48,49)}$.

\section{Government and community resource utilization}

The current study found that some DoD families, despite being employed, have to rely on government assistance programmes to provide enough food for their families. As previous reports have suggested, our findings indicate that FSSA, which is specifically designed for service members, is an underutilized programme ${ }^{(6,14)}$. Military leaders and community services employees may be unaware of the FSSA programme or unfamiliar with eligibility requirements and application procedures. On the other hand, service members may choose to participate in SNAP or WIC instead. Military members may choose to participate in SNAP because it is considered more 'generous' and does not require commander's approval ${ }^{(6)}$. It is also plausible that service members are underutilizing FSSA fearing stigma related to requesting such assistance through their military chain of command ${ }^{(6)}$. Household responses regarding community programmes indicated a strong desire for resources including cooking and budgeting classes. These are reasonable interventions that can be implemented on a local level.

\section{Strengths and limitations}

The present study was the first to look at food insecurity in DoD families, filling a research gap as there is a paucity of data regarding food security and use of food assistance programmes among the DoD community. Furthermore, the USDA Household Food Security Survey Module six-item short-form has been shown to have adequate sensitivity and specificity for detecting low and very low food security ${ }^{(40)}$. Our sample has similar characteristics to those reported in the 2014 Demographics: Profile of the Military Community for active-duty US military families. Comparable characteristics include the mean number of children, the largest proportion of children is under 6 years of age and the largest active-duty group with children by rank is non-commissioned officers ${ }^{(50)}$. Therefore, our sample may be representative of the larger target population. Additionally, the mixed-mode survey allowed busy families to participate whichever way was more convenient and there was no significant difference in food security status between those who participated electronically or on paper copy.

The current study does have limitations. JBSA is predominantly a training installation for the Army and Air Force, which may not be representative of the larger military population. Furthermore, JBSA is located in a large metropolitan area, which may not compare with several other military installations that are more remote. The prevalence of food insecurity in DoD families may be an underestimate because of CDC eligibility requirements. For instance, priority for childcare is given to full-time working parents or caregivers according to Army Regulation 608-10. In order to use the facilities, families have to pay a prorated amount based on total family income. These eligibility requirements may have excluded families most at risk for food insecurity from our study. Lastly, the demographic survey was not a validated questionnaire, but it was reviewed by a panel of six subject-matter experts for face and content validity.

\section{Implications}

The current study described the prevalence of food insecurity, identified key head of household demographics and household characteristics associated with food insecurity, and described resource utilization among food-insecure DoD families. Food insecurity is evident in this population and our results are likely to underestimate food insecurity for the overall military population for the reasons described above, indicating a need for a wider evaluation in a military population. Despite this, our results can be useful for Congress, policy makers, military commanders and health-care providers because food insecurity can be detrimental to the readiness and resiliency of the force since it has been associated with chronic disease, depression, poor diet quality and weight status ${ }^{(16,24,26,27,51-54)}$.

With the information presented herein, law makers and policy writers can make more informed decisions about military benefits that could potentially affect food security such as pay, allowances and commissary access. Furthermore, screening for food insecurity could be included in EFMP applications and those who were found to be experiencing limited access to adequate food could be given wider support. Future research can also explore specific risk factors related to EFMP participation to make screening more targeted. Food security status could also be assessed in the Health Related Behaviors Survey of military members to assess a wider population.

Military commanders and dietitians working with the DoD community can improve their awareness of those who may be most at risk for food insecurity and be able to offer help by becoming familiar with available resources like FSSA. However, the National Defense Authorization Act for Fiscal Year 2016 (H.R. 1735) proposes eliminating the FSSA programme in stateside duty locations where SNAP is available to service members ${ }^{(55)}$. If the FSSA programme continues, knowledge of this resource should be expanded by incorporating information into curriculums of advanced military leadership courses for non-commissioned officers and officers. Efforts should be made to eliminate the stigma associated with this programme ${ }^{(6)}$. If FSSA is discontinued, funding could be allocated to community programmes that address food 
insecurity. For example, Army Community Services, Family and Morale, Welfare and Recreation Programs, and related services could partner with military installation dietitians, public health nurses and local organizations to offer cooking and expanded budgeting classes. Lastly, families should be educated on the potential saving at military commissaries ${ }^{(37)}$.

Future research should focus on assessing a wider military population, exploring EFMP risk factors, determining utilization of other resources available to DoD families and conducting a more comprehensive needs assessment. Furthermore, quantifying the effects of food insecurity on the readiness of the fighting force is warranted. Armed with this information, the DoD will be capable of preventing detrimental effects of food insecurity on the readiness and resiliency of its families.

\section{Acknowledgements}

Acknowledgements: The authors would like to thank LTC Kerryn Story for her advice and expertise and the JBSA-CDC for supporting this project. Financial support: This work was supported by the Retired Army Medical Specialist Corps Association. Funding was provided for participation incentives. The funder had no role in the design, analysis or writing of this article. Conflict of interest: None. Authorship: S.G.W. participated in recruitment, worked on data analysis and wrote the manuscript. S.M.S. aided in formulating the research question and study design, recruitment, data analysis and editing the manuscript. Etbics of buman subject participation: This study was conducted according to the guidelines laid down in the Declaration of Helsinki and all procedures involving human subjects/ patients were approved by the Brooke Army Medical Center Institutional Review Board. Informed consent was not required for this survey-based study. Disclaimer: The views expressed herein are those of the authors and do not reflect the official policy or position of Brooke Army Medical Center, the US Army Medical Department, the US Army Office of the Surgeon General, the Department of the Army, the DoD or the US Government.

\section{References}

1. Coleman-Jensen A, Gregory C \& Singh A (2014) Household Food Security in the United States in 2013. Economic Research Report no. ERR-173. Washington, DC: US Department of Agriculture, Economic Research Service.

2. Andersen S (editor) (1990) Core indicators of nutritional state for difficult-to-sample populations. J Nutr 120, Suppl. 11, 1559-1600.

3. US Department of Agriculture, Economic Research Service (2014) Food Security in the US: Measurement. http://www. ers.usda.gov/topics/food-nutrition-assistance/food-securityin-the-us/measurement.aspx (accessed July 2015).

4. US Department of Agriculture (2015) Supplemental Nutrition Assistance Program Eligibility. http://www.fns.usda. gov/snap/eligibility (accessed January 2016).
5. Defense Finance Accounting Services (2015) Military Pay Charts. http://www.dfas.mil/militarymembers/ payentitlements/military-pay-charts.html (accessed January 2016).

6. Military Compensation and Retirement Modernization Commission (2015) Report of the Military Compensation and Retirement Modernization Commission. Final Report. Arlington, VA: Military Compensation and Retirement Modernization Commission.

7. US Department of Health and Human Services (2015) 2015 Poverty Guidelines. https://aspe.hhs.gov/2015-povertyguidelines (accessed January 2016).

8. Department of Defense (2016) Regular Military Compensation (RMC) Calculator. http://militarypay.defense.gov/ Calculators/RMCCalculator.aspx (accessed January 2016).

9. US Department of Agriculture, Food and Nutrition Service (2012) Retailer Policy \& Management Division 2012 Annual Report. Alexandria, VA: Benefit Redemption Division.

10. US Department of Agriculture, Food and Nutrition Service (2013) Supplemental Nutrition Assistance Program Retailer Management 2013 Annual Report. Alexandria, VA: Benefit Redemption Division.

11. US Department of Agriculture, Food and Nutrition Service (2014) Quick Facts: SNAP Participation Among Members of the Armed Forces. Alexandria, VA: Office of Policy Support.

12. Under Secretary of Defense for Personnel and Readiness (2008) Family Subsistence Supplemental Allowance (FSSA) Program. Department of Defense Instruction 1341.11. Washington, DC: Department of Defense.

13. Eslami E, Filion K \& Strayer M (2011) Characteristics of Supplemental Nutrition Assistance Program Housebolds: Fiscal Year 2010. SNAP-11-CHAR. Alexandria, VA: US Department of Agriculture, Food and Nutrition Service, Office of Research and Analysis.

14. Hosek J \& Wadsworth SM (2013) Economic conditions of military families. Future Child 23, issue 2, 41-59.

15. Widome R, Jensen A, Bangerter A et al. (2015) Food insecurity among veterans of the US wars in Iraq and Afghanistan. Public Health Nutr 18, 844-849.

16. Holben DH (2010) Position of the American Dietetic Association: food insecurity in the United States. J Am Diet Assoc 110, 1368-1377.

17. Kirkpatrick SI, McIntyre L \& Potestio ML (2010) Child hunger and long-term adverse consequences for health. Arch Pediatr Adolesc Med 164, 754-762.

18. Larson NI \& Story MT (2011) Food insecurity and weight status among US children and families: a review of the literature. Am J Prev Med 40, 166-173.

19. Rose-Jacobs R, Black MM, Casey PH et al. (2008) Household food insecurity: associations with at-risk infant and toddler development. Pediatrics 121, 65-72.

20. Skalicky A, Meyers AF, Adams WG et al. (2005) Child food insecurity and iron deficiency anemia in low-income infants and toddlers in the united states. Matern Child Health J 10, $177-185$

21. Weinreb L, Wehler C, Perloff J et al. (2002) Hunger: its impact on children's health and mental health. Pediatrics 110, e41.

22. Zaslow M, Bronte-Tinkew J, Capps R et al. (2008) Food security during infancy: implications for attachment and mental proficiency in toddlerhood. Matern Child Health J 13, 66-80.

23. Seligman HK, Laraia BA \& Kushel MB (2010) Food insecurity is associated with chronic disease among low-income NHANES participants. J Nutr 140, 304-310.

24. Whitaker RC, Phillips SM \& Orzol SM (2006) Food insecurity and the risks of depression and anxiety in mothers and behavior problems in their preschool-aged children. Pediatrics 118, e859-e868. 
25. Ding M, Keiley MK, Garza KB et al. (2015) Food insecurity is associated with poor sleep outcomes among US adults. J Nutr 145, 615-621.

26. Tayie FA \& Zizza CA (2009) Food insecurity and dyslipidemia among adults in the United States. Prev Med 48, 480-485.

27. Seligman HK, Bindman AB, Vittinghoff E et al. (2007) Food insecurity is associated with diabetes mellitus: results from the National Health Examination and Nutrition Examination Survey (NHANES) 1999-2002. J Gen Intern Med 22, 1018-1023.

28. Bartfeld J \& Dunifon R (2006) State-level predictors of food insecurity among households with children. J Policy Anal Manage 25, 921-942.

29. Stuff JE, LaCour M, Du XL et al. (2009) The prevalence of food insecurity and associated factors among households with children in Head Start programs in Houston, Texas and Birmingham, Alabama. Race Gender Class 16, 31-47.

30. Laraia BA, Borja JB \& Bentley ME (2009) Grandmothers, fathers, and depressive symptoms are associated with food insecurity among low-income first-time African-American mothers in North Carolina. J Am Diet Assoc 109, 1042-1047.

31. Military Community and Family Policy (2013) 2013 Demographics: Profile of the Military Community. Washington, DC: Office of the Deputy Assistant Secretary of Defense.

32. Clever M \& Segal D (2013) The demographics of military children and families. Future Child 23, 13-39.

33. Hosek J, Asch BJ, Fair CC et al. (2002) Married to the Military: The Employment and Earnings of Military Wives Compared with Those of Civilian Wives. Santa Monica, CA: US National Defense Research Institute.

34. Savych B (2008) Effects of deployments on spouses of military personnel. PhD Thesis, The Pardee RAND Graduate School.

35. Lundquist J, Xu Z, Barfield W et al. (2015) Do black-white racial disparities in breastfeeding persist in the military community? Matern Child Health J 19, 419-427.

36. Andrew T (2014) DoD budget seeks cuts in BAH, commissary, tricare benefits. http://www.armytimes.com/ article/20140224/BENEFITS02/302240023/DoD-budget-seekscuts-BAH-commissary-Tricare-benefitsfiles/165/DoD-budgetseeks-cuts-BAH-commissary-Tricare-benefits.html (accessed July 2015).

37. Defense Commissary Agency (2015) Annual Financial Report: Fiscal Year 2014. Fort Lee, VA: Office of Management and Budget.

38. Dillman DA, Smyth JD \& Christian LM (2009) Internet, Mail, and Mixed-Mode Surveys: The Tailored Design Method, 3rd ed. Hoboken, NJ: John Wiley \& Sons, Inc.

39. Hamilton WL, Cook JT, Thompson WW et al. (1995) Household Food Security in the United States in 1995: Summary Report of the Food Security Measurement Project. Cambridge, MA: Abt Associates Inc.

40. Blumberg SJ, Bialostosky K, Hamilton WL et al. (1999) The effectiveness of a short form of the Household Food Security Scale. Am J Public Health 89, 1231-1234.
41. US Department of Agriculture, Economic Research Service (2012) US Household Food Security Survey Module: Six Item Short Form. Washington, DC: US Department of Agriculture, Economic Research Service.

42. US Department of Agriculture, Economic Research Service (2014) Definitions of Food Security. http://www.ers.usda. gov/topics/food-nutrition-assistance/food-security-in-the-us/ definitions-of-food-security.aspx (accessed March 2015).

43. Coleman-Jensen A, McFall W \& Nord M (2013) Food Insecurity in Households with Children: Prevalence, Severity, and Household Characteristics, 2010-11. Economic Information Bulletin no. EIB-113. Washington, DC: US Department of Agriculture, Economic Research Service.

44. US Bureau of Labor Statistics, Southwest Information Office (2015) San Antonio Area Economic Summary. http://www. bls.gov/regions/economic-summaries.htm\#TX (accessed February 2015).

45. Walls RT \& Dowler DL (2015) Disability and income. Rehabil Couns Bull 58, 146-153.

46. Coleman-Jensen A \& Nord M (2013) Food Insecurity Among Households with Working-Age Adults with Disabilities. Economic Research Report no. ERR-144. Washington, DC: US Department of Agriculture, Economic Research Service.

47. Barlas FM, Higgins WB, Pflieger JC et al. (2013) 2011: Department of Defense Health Related Behaviors Survey of Active Duty Military Personnel. Fairfax, VA: ICF International.

48. Buckley TC, Mozley SL, Bedard MA et al. (2004) Preventive health behaviors, health-risk behaviors, physical morbidity, and health-related role functioning impairment in veterans with post-traumatic stress disorder. Mil Med 169, 536-540.

49. Hoerster KD, Lehavot K, Simpson T et al. (2012) Health and health behavior differences: US military, veteran, and civilian men. Am J Prev Med 43, 483-489.

50. Military Community and Family Policy (2015) 2014 Demographics: Profile of the Military Community. Washington, DC: Office of the Deputy Assistant Secretary of Defense.

51. Champagne CM, Casey PH, Connell CL et al. (2007) Poverty and food intake in rural America: diet quality is lower in food insecure adults in the Mississippi Delta. J Am Diet Assoc 107, 1886-1894.

52. Franklin B, Jones A, Love D et al. (2012) Exploring mediators of food insecurity and obesity: a review of recent literature. J Community Health 37, 253-264.

53. Hanson KL \& Connor LM (2014) Food insecurity and dietary quality in US adults and children: a systematic review. Am J Clin Nutr 100, 684-692.

54. Seligman HK, Laraia BA \& Kushel MB (2010) Food insecurity is associated with chronic disease among low-income NHANES participants. J Nutr 140, 304-310.

55. 114th Congress (2015-2016) National Defense Authorization Act for Fiscal Year 2016, S. 2015, House, 114th Congress Sess. 